\title{
TRPV1 Antagonists as Analgesic Agents
}

\author{
Marcello Trevisani* and Raffaele Gatti
}

\author{
PharmEste srl, Via Saragat 1, 44121 Ferrara, Italy
}

\begin{abstract}
The last decade (2001 - 2010), declared as the Decade of Pain Control and Research by the United States Congress, brought significantly advances in our understanding of pain biology. Unfortunately, this has not translated into additional effective treatments of chronic pain conditions. Chronic pain is a debilitating and complex clinical state usually associated with diabetic neuropathy, postherpetic neuralgia, low back pathology, fibromyalgia, and neurological disorders. Standard pain drugs, even narcotic opioid analgesic agents, often provide unsatisfactory pain relief while causing important side-effect such as sedation, tolerance, dependence, respiratory depression and constipation. Furthermore, the effective management of chronic pain needs a multidisciplinary management approach and still represents one of the most urgent unmet medical need. Recently, preclinical research has uncovered new molecular mechanisms underlying the generation and transduction of pain, many of which represent new targets for innovative pharmacological interventions. This review focuses on Transient Receptor Potential (TRP) Vanilloid Type 1 (TRPV1) channel as a target for treating chronic pain. TRPV1 is a multifunctional ion channel involved in thermosensation (heat) and taste perception. Importantly, TRPV1 also functions as a molecular integrator for a broad variety of seemingly unrelated noxious stimuli. Indeed, TRPV1 is thought to be a major transducer of the thermal hyperalgesia that follows inflammation and/or tissue injury. Desensitization to topical TRPV1 agonists (e.g. capsaicin creams and patches) has been in clinical use for decades to treat chronic painful conditions like diabetic neuropathy. Most recently, a number of potent, small molecule TRPV1 antagonists have been advanced into clinical trials for pain relief. Perhaps not unexpectedly given the prominent role of TRPV1 in thermosensation, some of these antagonists showed worrisome adverse effects (hyperthermia and impaired noxious heat sensation) in humans, leading to their withdrawal from clinical trials. However, recent reports of TRPV1 antagonists that do not affect core body temperature in preclinical species suggest a potential opportunity to reduce at least this important side effect.
\end{abstract}

Keywords: Capsaicin, resiniferatoxin, transient receptor potential (TRP) channels, the capsaicin (vanilloid) receptor TRPV1, small molecule TRPV1 antagonists, chronic pain, neuropathic pain, hyperalgesia.

\section{INTRODUCTION}

Pain is among the most common reasons patients approach the health care community. Contrary to acute pain, that represents the response to an injury and lasts until the injury is healed, chronic pain persists, sometimes long after the healing process, and in some cases, the injury never heals causing an almost constant state of pain. Chronic pain is often associated with diabetic neuropathy, postherpetic neuralgia, low back pathology, fibromyalgia, cancer and neurological disorders such as depression and anxiety. It has been recently estimated that about 50 million United States citizens suffer from chronic pain, costing the country billions of dollars in health care costs and lost productivity [1]. Indeed, the neuropathic pain market in the United States is expected to double from today's $\$ 2.6$ billion to $\$ 5$ billion by 2018 . In recognition of this problem, the United States Congress declared 2001-2010 as the Decade of Pain Control and Research.

Unfortunately, despite our present depth of knowledge of the basic mechanisms underlying pain and the investment of

\footnotetext{
*Address correspondence to this author at the PharmEste srl, Via Saragat 1, 44121 Ferrara, Italy; Tel: : 00390532 455240; Fax: 00390532 974092; E-mail: marcello.trevisani1973@gmail.com
}

significant resources to identify novel analgesic drugs, chronic pain remains a significant unmet medical need. Part of the difficulty in developing successful treatments for chronic pain lies in our failure to resolve the complex interplay among mechanisms involved. To date, patients suffering from disabling pain conditions often need complex and aggressive treatment plans that combine medical and surgical approaches [2-4]. In addition, the field has struggled to develop drugs that provide relief devoid of central side effects such as dizziness and drowsiness that limit the patient's ability to carry out normal activities. The mainstay of medical pain therapy remains drugs that have been around for decades, like non-steroidal anti-inflammatory drugs (often referred to as NSAIDs), or even centuries, such as opiates [4]. Many patients, however, find over-the-counter NSAID medications ineffective for pain relief. Opiates are very powerful painkillers but their clinical use is limited by the adverse effects that they cause [5]. Also, many clinicians are concerned about abuse of prescription pain killers, in particular opiates [6]. This scenario indicates that the current therapeutic approach for chronic pain does not provide adequate relief to patients [7] and that there is a great need for new therapeutic agents in this field.

Over the past few years, however, significant scientific progress has been made in our understanding of the mecha- 
nisms that underlie pathologic pain. The differences and overlaps among nociceptive, inflammatory and neuropathic pain are beginning to be understood. Preclinical research has identified a large number of potential targets for drug discovery and mechanisms that are involved in the development and maintenance of chronic pain. A key discovery was the molecular cloning of the vanilloid (capsaicin) receptor TRPV1 (transient receptor potential (TRP), vanilloid subfamily member 1), a polymodal nociceptor expressed on primary sensory neurons [8] recognized as a heat-sensitive cation channel [9-11]. As many pro-algesic pathways converge on TRPV1 and this nocisensor is up-regulated and sensitized by inflammation and injury (see below) [9-13], TRPV1 is thought to be a central transducer of hyperalgesia and a prime target for the pharmacological control of pain. Together with TRPV1, other TRP channels such as TRPV2, TRPV3, TRPV4, TRPA1 and TRPM8, are implicated in sensory processing [14].

Very recently, a number of potent, small molecule TRPV1 antagonists have been advanced into clinical trials for the evaluation of analgesic activity. Some of these antagonists impaired noxious heat sensation and induced hyperthermia in healthy volunteers, leading to their withdrawal from the clinical trials. This review focuses on present evidence that supports the hypothesis that TRPV1 antagonists offer potential as new-generation analgesic drugs, along with potential adverse effects that may limit their clinical value.

\section{THE TRPV1 CHANNEL AND NOCICEPTION}

\section{Capsaicin, a Little Bit of "History"}

Capsaicin (8-methyl-N-vanillyl-6-nonenamide) and several related compounds called "capsaicinoids" are active components produced by chili peppers (Capsicum annum), probably as deterrents against certain herbivores and fungi. Capsaicin is an irritant for mammals, including humans, and produces a sensation of burning in any tissue with which it comes into contact. Moreover, it induces profuse perspiration (known as gustatory sweating) as well as a hot, burning sensation that dissipates upon repeated challenge (desensitization). Capsaicin is not only a spice, however, but an extremely versatile agent whose biological uses, covered by more than 900 patents, range from culinary applications (included to improve flavor and inhibit bacterial growth) through pain killers to chemical weapons and repellants.

Chili pepper is extensively used in folk medicine. Some uses are time-honored and are supported by modern science whereas others are puzzling (though harmless) or have a darker side. For example, the analgesic use of capsaicin was probably independently recognized by folk healers in various cultures. In India, chili pepper tea is strongly recommended for dental pain. Native Americans traditionally rub their gums with pepper pods to relieve tooth ache. This practice also gained popularity in Europe, as was noted by the Hungarian botanist-turned-clergyman Otto Hangay in 1887 [15]. As early as 1850, the Dublin Free Press recommended the use of alcoholic hot pepper extract on sore teeth [16]. These early observations by astute folk healers paved the way to the on-going clinical trials with selective, small molecule TRPV1 antagonists for tooth ache and post-molar extraction pain.
The modern pharmacology of capsaicin has its roots in the laboratory of Endre Högyes in Budapest, Hungary. In 1878 , he made the astute observation that the capsaicin acts on sensory nerve fibers [17] (see below). However, unlike other plant products such as nicotine and atropine which attracted tremendous interest capsaicin was by and large ignored by pharmacologists until the 1950's. It was the brilliant Hungarian pharmacologist Nicholas (Miklós) Jancsó who almost single-handedly transformed capsaicin from a spice (and pharmacological oddity) to a promising analgesic drug during the tumultuous years after the $2^{\text {nd }}$ World War. In 1949 , he observed that "there are compounds that can selectively desensitize sensory nerve endings to noxious chemical stimuli without causing local anesthesia [18]. Capsaicin is the archetypal of such desensitizing agents. Jancsó also postulated a central role for capsaicin-sensitive nerves in neurogenic inflammation [19].

Capsaicin got "rediscovered" in the late "70ies, as evidenced by the explosion of the literature from a few papers a year in 1977 [20, 21] to more than one a day in the late '80ies. As of today, the database of the National Library of Medicine lists 10,937 scientific papers on capsaicin. Capsaicin-containing creams (e.g. Zostrix) entered clinical practice to relieve pain associated with disease states like postherpetic neuralgia or diabetic polyneuropathy in the '80ies. Intravesical administration of capsaicin proved beneficial in patients with overactive bladder.

In 1990 [22], the specific binding of resiniferatoxin (4Hydroxy-3-methoxy-[(2S,3aR,3bS,6aR,9aR,9bR,10R,11aR) -3a,3b,6,6a,9a,10,11,11a-octahydro-6a-hydroxy-8,10-dimethyl-11a-(1-methylethenyl)-7-oxo-2-(phenylmethyl)-7H-2,9b-epoxyazuleno[5,4-e]-1,3-benzodioxol-5-yl] benzeneacetate), an ultrapotent capsaicin analogue isolated from the latex of the cactus-like perennial $E$. resinifera, furnished the first biochemical proof for the existence of the long soughafter capsaicin receptor [23-26]. After this discovery, it took only seven years to clone the TRPV1 receptor [27], employing an expression cloning strategy based on capsaicinevoked $\mathrm{Ca}^{2+}$ uptake. The importance of TRPV1 as a pain sensor was validated by both deletion of the TRPV1 gene $[28,29]$ and knock-down of TRPV1 by RNA interference [30-32].

Capsaicin has long been used as a topical analgesic agent to relieve chronic pain associated with postherpetic neuralgia, diabetic neuropathy and rheumatoid arthritis [33-35]. Moreover, it was recommended for musculoskeletal pains such as muscle strains and back ache. In the US, capsaicin is available as an over-the-counter (OTC) cream at concentrations of $0.075 \%$ or less under brand names like Axsain $(0.025 \%$ capsaicin mixed with lidocaine) and Zostrix $(0.075 \%)$.

Desensitization to TRPV1 agonists (e.g. capsaicin and resiniferatoxin) is a powerful approach to relieve symptoms of nociceptive behavior in animal models of chronic pain. At present, both capsaicin-containing patches (Qutenza by Astellas Pharma, formerly NGX-4010 by NeurogesX) and site-specific, injectable capsaicin preparations (Adlea by Anesiva) are undergoing clinical trials in both oncologic and non-oncologic patient populations for the indication of chronic, intractable pain. The ultrapotent capsaicin analog, resiniferatoxin, is moving into Phase 1 and 2 clinical trials at 


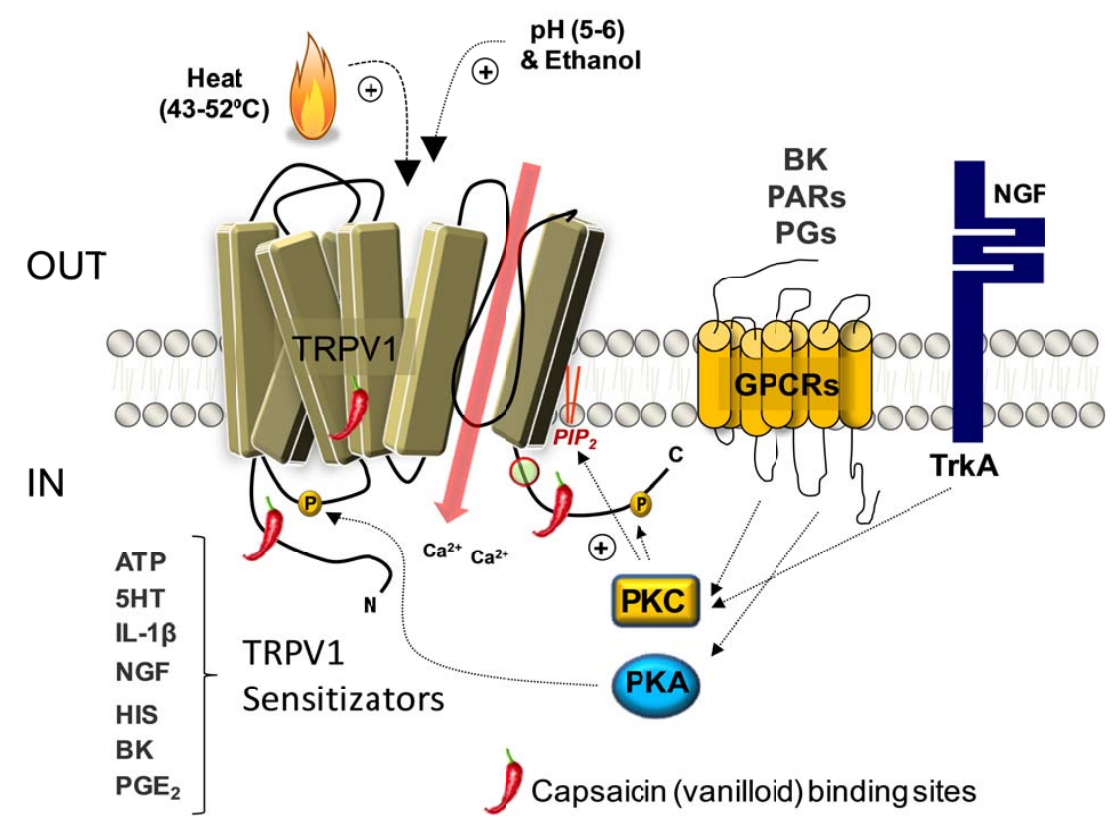

Fig. (1). Peripheral sensitization of TRPV1 expressed on terminals of primary sensory neurons. TRPV1 is receptive to pro-inflammatory agents such as prostaglandins ( $\mathrm{PGs}, \mathrm{PGE}_{2}$ ), bradykinin (BK), adenosine triphosphate (ATP), 5-hydroxytryptamine (5HT), protease activate receptors (PARs) 1, 2 and 4, nerve growth factor (NGF) and interleukin-1 beta (IL-1 $\beta$ ) that cause allosteric modification of the channel protein, either directly or indirectly, such that the probability of channel opening by heat, protons and vanilloids is enhanced.

the National Cancer Institute to treat severe pain associated with advanced cancer [36].

\section{TRPV1 as Polymodal Sensor Expressed on Peptidergic Sensory Neurons}

Generally speaking, pain is perceived when action potentials generated in nociceptive neurons are transmitted to the somatosensory cortex. These neurons express a variety of ion channels, many of which represent potential targets for analgesic drugs [37]. A subset of nociceptive neurons is distinguished by its unique sensitivity to capsaicin. In the skin, capsaicin causes an itching, pricking or burning sensation and produces cutaneous vasodilatation (flare response) and edema formation. After this initial acute neuronal excitation, a period of enhanced sensitivity to heat (thermal hyperalgesia) is established. Alternatively (after repeated challenge or when high doses are used), the previously excited neurons develop a lasting refractory state (traditionally referred to as desensitization) in which they are unresponsive not only to capsaicin but also various unrelated chemical and physical stimuli. This capsaicin sensitivity is long considered as a functional signature of primary sensory neurons with thinmyelinated A $\delta$ and unmyelinated C-fibers, hence the term capsaicin-sensitive afferent neurons. These neurons have somata in sensory ganglia (dorsal root, trigeminal and vagal), reveal slow conduction capacity, and respond to noxious thermal, mechanical and chemical stimuli.

Upon stimulation, TRPV1-expressing, thus capsaicinsensitive, primary sensory neurons release a variety of proinflammatory neuropeptides (e.g. substance P [SP], calcitonin gene-related peptide [CGRP], and neurokinin A [NKA]) that initiate a cascade of biochemical events, globally defined as neurogenic inflammation [38]. Neurogenic inflammation is thought to play a central role in the patho- genesis of various disease states that range from migraine through asthma to inflammatory bowel disease [38, 39].

TRPV1 is a polymodal receptor, sensitive to noxious heat (above $43{ }^{\circ} \mathrm{C}$, Fig. (1)), acidosis (pH between 5 and 6), "endovanilloids" (e.g. anandamide, arachidonic acid metabolites such as N-arachidonoyl-dopamine [NADA], 12-hydroperoxyeicosatetraenoic acid, oxidized linoleic acid metabolites, essential oils, octadecadienoids), and a variety of pungent plant products as exemplified by capsaicin (responsible for the piquancy of hot chilli peppers), resiniferatoxin, piperine (the pungent ingredient in black pepper), gingerol and zingerone (from ginger), camphor, as well as eugenol (a powerful essential oil found in cloves). Interestingly (and somewhat unexpectedly), TRPV1 is also activated by ethanol and venoms from jellyfish and spiders [9, 40-49].

In addition, TRPV1 is receptive to pro-inflammatory agents such as prostaglandins, bradykinin, adenosine triphosphate (ATP), 5-hydroxytryptamine, protease activate receptors (PAR) 1, 2 and 4, nerve growth factor (NGF) and tumor necrosis factor alpha (TNF-alpha) [50] that cause allosteric modification of the channel protein, either directly or indirectly, such that the probability of channel opening by heat, protons and capsaicin is enhanced [9, 40, 43, 51-54] Fig. (1). Thus, TRPV1 functions as a molecular integrator of painful stimuli in which each stimulus sensitizes the channel to other stimuli, with the end-result that TRPV1 acts as a molecular amplifier in the sensory neuron [55]. Interestingly, TRPV1 (perhaps together with TRPA1) is also responsible for the paradox painful action of the commonly used general anaesthetic drug propofol [56].

The well-documented property of TRPV1 to become sensitized when exposed to painful stimuli has led to the hypothesis that TRPV1 is a prime contributor to the development of thermal hyperalgesia [57], which, in turn, is be- 
lieved to be secondary to "peripheral sensitization" Fig. (1). TRPV1 sensitization depends on several mechanisms among which phosphorylation of TRPV1 by protein kinase A (PKA), protein kinase $\mathrm{C}$ (PKC) and other kinases Fig. (1) is of pivotal importance [51, 58-65]. In fact, several inflammatory mediators (e.g. prostaglandins) enhance activation of TRPV1 by capsaicin and/or heat via a PKA-dependent pathway. Other mediators including bradykinin, NGF and anandamide were reported to increase TRPV1 activity through phospholipase C (PLC)-mediated hydrolysis of phosphatidylinositol-4,5-bisphosphate $\left(\mathrm{PIP}_{2}\right)$ [66]. In keeping with this, it was postulated that TRPV1 is under the inhibitory control of $\mathrm{PIP}_{2}$. Subsequent studies, however, reported the opposite effect (tachyphylaxis) on TRPV1 for $\mathrm{PIP}_{2}$ hydrolysis. Although it has been demonstrated that $\mathrm{PIP}_{2}$ could bind to both $\mathrm{C}$ - and $\mathrm{N}$-terminus of the channel (that may provide a rational to explain differential actions), there is continuing controversy regarding the net effect of $\mathrm{PIP}_{2}$ on TRPV1 [6770].

Conversely, dephosphorylation of TRPV1 by protein phosphatases (e.g. calcineurin) promotes desensitization and represents a major mechanism of inhibitory regulation [71]. Desensitization of TRPV1 to capsaicin also involves a number of intracellular components including PKA, ATP and calmodulin [68, 72-75]. There appears to be a dynamic balance between phosphorylation and dephosphorylation of the TRPV1 channel that controls the activation/desensitization state of the channel [71, 76].

Combined, these findings identify TRPV1 as a promising target to relieve inflammatory (and possibly also neuropathic and visceral) pain Fig. (1). Indeed, inactivation of TRPV1 by either genetic deletion [28, 29] or pharmacological blockade experiments was reported to ameliorate heat hyperalgesia in rodent models of inflammatory pain [43, 77-80].

The rationale for using potent and selective small molecule TRPV1 antagonists to relieve inflammatory pain is the concept that TRPV1 may be directly activated by agents that are present in the inflammatory soup, the so-called "endovanilloids" (reviewed in [12, 43]) Fig. (1). In other words, TRPV1 antagonists are expected to prevent activation of TRPV1 by endovanilloids. Indeed, a number of agents in inflammatory soup as well as substances generated during exposure to noxious heat were implicated as potential endovanilloids.

\section{PRE-CLINICAL OVERVIEW OF TRPV1 ANTAGO- NISTS}

Consistent with the high level of preclinical validation for TRPV1 as a pain target, many pharmaceutical companies have initiated drug screening and lead optimization programs. An array of potent and selective small molecule TRPV1 antagonists were identified, many of which are currently being evaluated in the clinic as analgesic drugs [8186] Fig. (2) and Table 1.

Capsazepine, the first described competitive TRPV1 antagonist, was discovered by a research group at the Sandoz Institute for Medical Research. It was found by modification of the chemical backbone of capsaicin [87]. Though extremely useful in the research laboratory, capsazepine was a poor clinical candidate. Importantly, capsazepine is not selective for TRPV1; in fact, it inhibits nicotinic and voltage- gated calcium channels (reviewed in [26, 43]), as well as TRPM8 [88, 89]. Moreover, capsazepine was much more effective in reversing partial sciatic nerve ligation-induced mechanical hyperalgesia in guinea pig than in mice or rats with neuropathic and inflammatory pain [90]. This "not ideal" pharmacological profile of capsazepine has led to the development of new, potent and selective TRPV1 antagonists from most of the major pharmaceutical companies (as well as many small biotech companies). These efforts have resulted in the identification of a large (and still growing) number of potent and efficacious TRPV1 antagonists (reviewed in [78-80, 91]).

However, not unexpectedly, some of these new TRPV1 blockers turned out to be stimulus-specific whereas others appear to block several means of activation [92, 93]. For instance, AMG0610 (from Amgen) and SB-366791 (developed by GlaxoSmithKline) inhibit the activation of rat TRPV1 by capsaicin but not by acid, whereas I-RTX, BCTC, AMG6880, AMG7472, AMG9810 and A-425619 are TRPV1 antagonists that do not differentiate between capsaicin and protons [92, 94-96]. Compound AMG8562 does not block heat-evoked activation of rat TRPV1 [93].

Several structurally different TRPV1 antagonists such as capsazepine, BCTC (Pardue Pharma), A-784168 (Abbott), GRC-6211 (Glenmark) and the quinazolinone "Compound 26 " are reported to decrease hypersensitivity in neuropathic animals [97-105]. Another Abbott molecule, A-889425, inhibited responses of slowly conducting $A \delta$ fiber units to noxious mechanical stimulation in a population of axons innervating CFA-inflamed hind paws [106].

Other potent and selective TRPV1 antagonists of both human and rat TRPV1 receptors, the 1-isoquinolin-5-yl-3-(4trifluoromethyl-benzyl)urea, A-425619 (Abbott) and compound PHE377 (PharmEste), proved dose dependently effective in several models of inflammatory and neuropathic pain without altering motor and memory/learning performances [107, 108].

The TRPV1 receptor antagonist from Abbott, ABT-102, exhibited analgesic properties in several rodent pain models, including chronic inflammatory, bone cancer, and postoperative pain. Another Abbott molecule (ABT-116) exhibited potent in vitro and in vivo activity, possessing a suitable profile for advancement to clinical development for pain management [109-112].

Compound A-995662 exhibited anti-pain effect in a model of rat knee joint pain partly by reducing the release of glutamate and CGRP from the spinal cord [113]. Furthermore, the TRPV1 antagonist, JNJ-39729209, was recently reported to significant ameliorate carrageenan- and CFAevoked thermal hyperalgesia [114].

The recently disclosed TRPV1 antagonist, AS1928370, from Astellas, significantly and potently improved mechanical allodynia in an L5/L6 spinal nerve ligation model in rats $\left(\mathrm{ED}_{50}\right.$ of $0.26 \mathrm{mg} / \mathrm{kg}$ ) when orally administered. AS 1928370 alleviated inflammatory pain in a CFA model at $10 \mathrm{mg} / \mathrm{kg}$, as well [104, 115]. Importantly, the intrathecal administration of $\operatorname{AS} 1928370$ (30 $\mu \mathrm{g} / \mathrm{body})$ also significantly suppressed mechanical allodynia in mice. Another Astellas molecule, AS1725195, was orally bioavailable and showed significant effects on segmental spinal nerve ligation model 
$\left(\mathrm{ED}_{50}\right.$ of $0.71 \mathrm{mg} / \mathrm{kg}$ ) and chronic constriction injury model $\left(\mathrm{ED}_{50}\right.$ of $\left.1.2 \mathrm{mg} / \mathrm{kg}\right)$ in rats [105].

'It should be mentioned here that preclinical models of pain may result in an underestimation of the clinical utility of TRPV1 antagonist because they do not adequately address the extent of spontaneous or ongoing pain [116]. It is also worth noting that while pain due to cancer may only partly arise from neuropathy, TRPV1 antagonists have exhibited effectiveness in models of cancer pain $[117,118]$.

\section{HYPERTHERMIA CAUSED BY TRPV1 BLOCKADE}

It is well known that the agonist capsaicin transiently decreases body temperature in various species, including man, by operating the TRPV1 channel $[26,119]$. In the course of evaluating the ability of TRPV1 antagonists to block capsaicin-induced hypothermia, it was found that some of them caused hyperthermia per se [101, 120, 121]. These results appeared unexpectedly because TRPV $1^{(-1)}$ mice have an apparently normal body temperature and rats whose TRPV1-expressing neurons have been ablated by high-dose neonatal capsaicin administration do not show hyperthermia either.

The question which still remains to be answered unequivocally is whether the hyperthermic action of TRPV1 antagonists is un-separable from their analgesic action. The hyperthermic action of some TRPV1 antagonists was first reported in 2006 at the Spring Pain Conference, Cayman Islands. It was noted that the increase in body temperature was moderate $\left(\sim 0.5^{\circ} \mathrm{C}\right)$; it could be mitigated by common antipyretic drugs like acetaminophen; and it disappeared ("desensitized") upon repeated administration. It was, however, worrisome that the febrile reaction was exacerbated in animals exposed to bacterial endotoxins (LPS).

Two years later, Amgen announced the early termination of a Phase 1b dental pain (molar extraction) study with their clinical candidate molecule, AMG517, because it caused a lasting (1-4 days) marked hyperthermia response (up to 40.2 $\left.{ }^{\circ} \mathrm{C}\right)$ in human volunteers. This finding provided the experimental foundation for the concept (most recently refuted by Romanovsky and colleagues, [122]) that the predominant function of TRPV1 is body temperature regulation [123]. It was postulated that TRPV1 has an endogenous tone which is important for the maintenance of normal body temperature $[121,124]$. If this tone is increased (for example by administering an exogenous TRPV1 agonist such as capsaicin), core temperature starts dropping. Conversely, decreasing the tone by TRPV1 antagonists leads to hyperthermia. This simple model is, however, inconsistent with the experimental findings. The hypothermic activity of capsaicin has been firmly linked to the preoptic area. Capsaicin when microinjected into this brain nucleus causes a marked hypothermic response. By contrast, the low CNS penetrant TRPV1 antagonist, AMG0347, is not more effective in causing hyperthermia when administered into the brain (intracerebroventricularly) or spinal cord (intrathecally) than when given systemically (intravenously) [125]. This observation was interpreted to imply that TRPV1 expressed on a peripheral site mediates the effect of TRPV1 antagonist on core body temperature. In other words, the sites that are responsible for the hypothermic activity of capsaicin (preoptic area) and hyperthermic action of TRPV1 antagonists are anatomically distinct. The site that mediates the febrile reaction of the antagonists is now believed to be in the abdomen, probably the GI tract (though this concept has been questioned recently) [125].

Several strategies were tried to mitigate the hyperthermic action of TRPV1 antagonists. Similar to agonist-induced hypothermia that disappears after repeated administration, antagonist-induced hyperthermia also shows attenuation after repeated dosing [126]. It was suggested that the initial hyperthermia can be adequately managed by common antipyretic agents like acetaminophen. A more attractive approach is to eliminate the undesirable side-effect of TRPV 1 antagonists on thermoregulation by chemical modification of the pharmacophore. In the rat, it was feasible to eliminate hyperthermia while preserving antihyperalgesia by differential modulation of distinct modes of TRPV1 activation. Compounds (e.g. AMG8562) that prevented the activation of rat TRPV1 by capsaicin, but not by low $\mathrm{pH}$ (referred to as Profile C antagonists), had no effect on body temperature [93]. Finally, the Abbott group disclosed that acid sparing TRPV1 antagonists do not significantly increase core body temperature [127].

Very recently, it has been described that the TRPV1 antagonist, BCTP, does not induce significant hyperthermia in rodents at doses providing analgesia [128]. Other potent TRPV1 antagonists (GRC6211, PHE377 and AS1928370) appear to be devoid of any febrile reaction when administered to rodents or dogs. Indeed, AS1928370 did not increased rectal body temperature up to $10 \mathrm{mg} / \mathrm{kg}$ oral treatment, although a significant hypothermic effect was noted at $30 \mathrm{mg} / \mathrm{kg}$ [104, 105].

At present, there is no mechanistic explanation why some TRPV1 antagonists elevate body temperature whereas others do not.

\section{TRPV1 ANTAGONISTS AND LOSS OF WARM THERMAL PERCEPTION IN HUMANS}

In keeping with its function as a noxious heat sensor, an impaired detection of painful heat was described in TRPV 1 knockout mice [28]. Moreover, TRPV1 antagonists were reported to elevate the withdrawal reflex threshold in response to noxious heat in preclinical species [129-131].

Most recently, clinical studies have confirmed the role of TRPV1 as a noxious heat sensor in humans demonstrating the involvement of the channel in heat perception in healthy volunteers. Indeed, heat pain threshold was significantly elevated in non-sensitized skin of healthy volunteers following $400 \mathrm{mg}$ SB-705498 (GlaxoSmithKline) oral administration [81, 132]. Subsequently, investigators at MerckNeurogen have reported that compound MK-2295 markedly blunted heat perception in healthy human subjects (quantitative thermal sensory tests, pain evoked by hand immersion into or sipping hot water) with no sign of tachyphylaxis [131, 133]. Similar results were observed by AstraZeneca with the TRPV1 antagonist, AZD1386. AZD1386 was investigated in two Phase 1 trials in healthy volunteers and found to increase mean thresholds for heat-induced pain [132]. Interestingly, the enhancement in heat pain threshold persisted after repeated dosing of compound AZD1386.

The enhanced heat pain threshold and tolerance induced by TRPV1 antagonists in healthy volunteers (which is appar- 

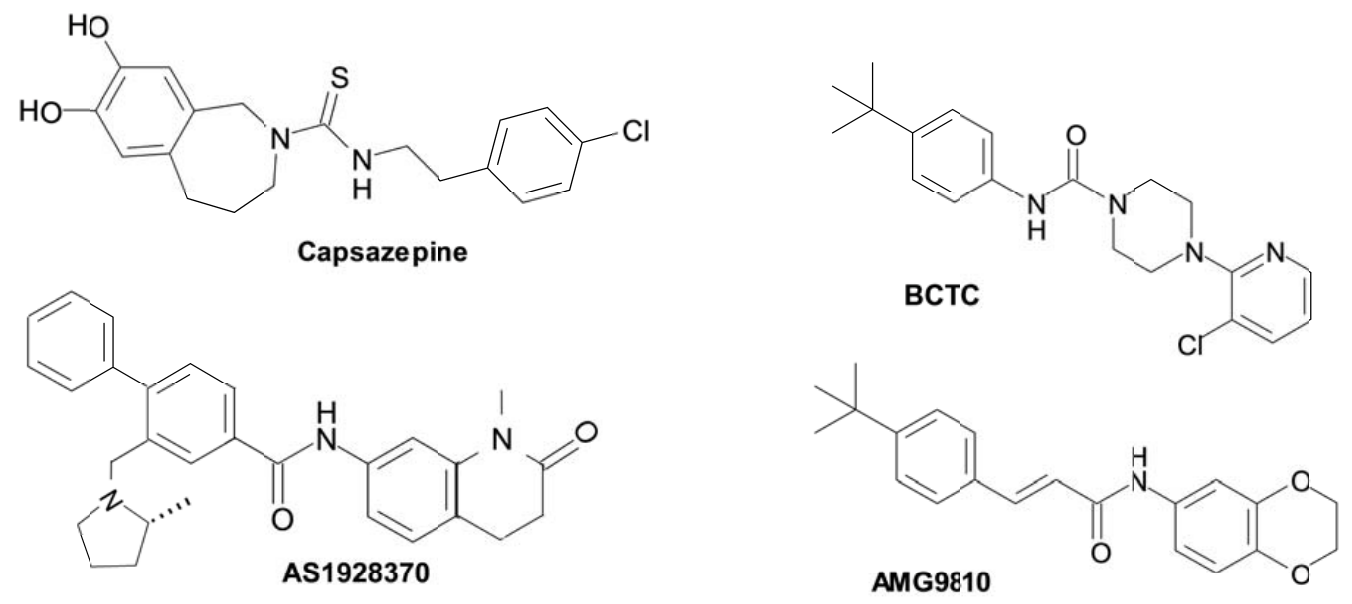<smiles>CC(C)(C)c1ccc2c(c1)CC[C@H]2NC(=O)Nc1cccc2[nH]ncc12</smiles><smiles>O=C(NCc1ccc(C(F)(F)F)cc1)Nc1cccc2cnccc12</smiles><smiles>O=C([OH2+])Nc1nc2c(Oc3cc(-c4ccc(C(F)(F)F)cc4)ncn3)cccc2s1</smiles>

AMG 517

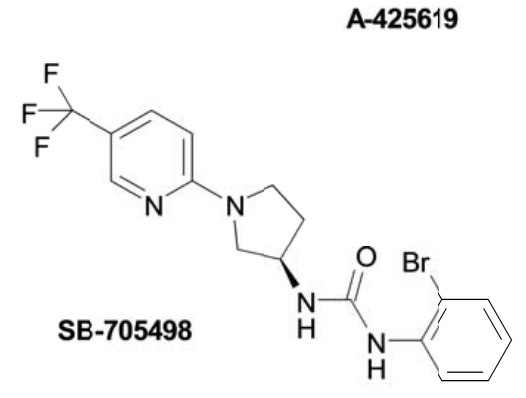

Fig. (2). Selected chemical structures of diverse TRPV1 antagonists. Chemical names of the compounds are: Capsazepine, N-[2-(4Chlorophenyl)ethyl]-1,3,4,5-tetrahydro-7, 8-dihydroxy-2H-2-benzazepine-2-carbothioamide; BCTC, N-(4-Tertiarybutylphenyl)-4-(3cholorphyridin-2-yl)tetrahydropyrazine-1(2H)-carbox-amide; AS1928370, (R)-N-(1-Methyl-2-oxo-1,2,3,4-tetrahydro-7-quinolyl)-2-[(2methylpyrrolidin-1-yl)methyl]biphenyl-4-carboxamide; AMG9810, (E)-3-(4-t-butylphenyl)-N-(2,3-dihydrobenzo[b] [1, 4] dioxin-6yl)acrylamide; ABT-102, (R)-(5-tert-butyl-2,3-dihydro-1H-inden-1-yl)-3-(1H-indazol-4-yl)-urea; A-425619, Nisoquinolin-5-yl-N-[4(trifluoromethyl)benzyl]urea; AMG 517, N-(4-[6-(4-trifluoromethyl-phenyl)-pyrimidin-4-yloxy]-benzothiazol-2-yl)-Acetamide and SB708495, N-(2-bromophenyl)-N-[((R)-1-(5-trifluoromethyl-2-pyridyl)pyrrolidin-3-yl)]urea. Chemical structures of compounds DWP-05195, PHE377, AZD-1386, GRC-6211 and JTS-653 have not been disclosed so far.

ently greater than those observed in pre-clinical species) is worrisome for its potential to cause scalding injury. Indeed, some subjects taking MK-2295 perceived potentially harmful temperatures as innocuous. These individuals could have suffered scalding injuries when taking hot shower or drinking hot coffee. Importantly, the effect of TRPV1 antagonists on heat pain sensation does not attenuate after multiple dosages.

As mentioned above, the TRPV1 selective antagonist, ABT-102, demonstrated efficacy in multiple preclinical pain models. However, evolving clinical data for this compound class suggested potentially profound drug-induced thermosensory impairment. In a multiple-dose, double-blind, placebo-controlled, randomized healthy volunteer trial, ABT-102 dose-dependently increased heat pain thresholds and reduced painfulness of suprathreshold heat. These unde- sired effects were observed during the entire administration regimen and reversed during the three follow-up days. No impairment in oral and cutaneous cold detection was reported $[134,135]$.

\section{CLINICAL EXPERIENCE WITH TRPV1 ANTAGO- NISTS}

Although several small molecule TRPV1 antagonists are currently undergoing Phase 1 and 2 clinical trials for indications related to pain Fig. (2) and Table 1, many others showed worrisome adverse effects in men, leading to their withdrawal from the clinical trials.

Daewoong Pharmaceutical has received approval from the KFDA (Korean Food and Drug Administration) to enter into clinical trials with compound DWP05195 for oral treatment of neuropathic pain. By July 2011, the Korean Ministry 
Table1. Clinical trial status of TRPV1 antagonists.

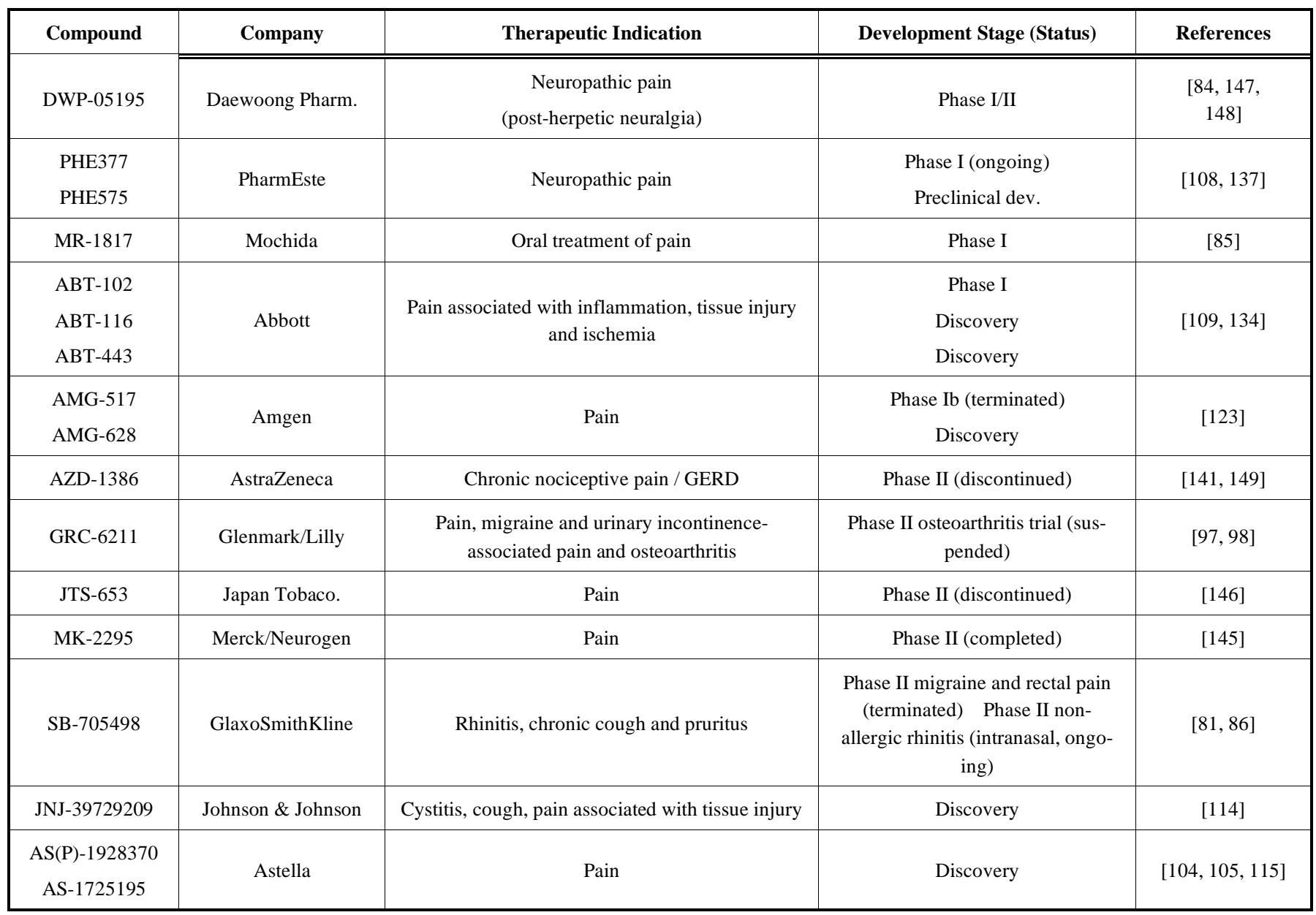

of Health had selected DWP05195 as a project to financially support. In August 2011 a Phase 2 trial in patients with post herpetic neuralgia began. [84, 136].

Compound PHE377 [137], a potent TRPV1 antagonist developed by PharmEste to treat diabetic neuropathic pain and post herpetic neuralgia, is currently undergoing a Phase 1 clinical trial. A second generation TRPV1 antagonist, PHE575, is in preclinical development stage [83].

Mochida, following the reacquisition of wrights from Wyeth/Pfizer is developing MR-1817 for the oral treatment of pain. A Phase 1 trial was completed in 2011. However, no information on Phase I results have been disclosed so far [85].

In 2007, GlaxoSmithKline disclosed its Phase 1 results obtained with its selective and potent TRPV1 antagonist, SB-705498. In the first part of the study, single doses of SB705498 ranging from 2 to $200 \mathrm{mg}$ did not display efficacy in the capsaicin-evoked flare test [81]. However, in the second part of the study, a single oral dose of $400 \mathrm{mg}$ SB-705498 substantially reduced pain from cutaneous capsaicin challenge $(0.075 \%$ capsaicin cream applied to the forearm) compared to placebo. Importantly, SB-705498 did not show any serious adverse effects in the study. In December 2005, an active-controlled, placebo-controlled, randomized, singleblind, Phase 2 trial (NCT00281684, VRA105345) was initi- ated in subjects with dental pain following third molar tooth extraction. The subjects were to receive a single oral dose of SB-705498, placebo or co-codamol. The study was completed by February 2008 and no results have been revealed, yet [138]. Topical formulations of SB-705498 have been recently evaluated in two Phase 2 clinical trials in chronic cough and non allergic rhinitis patients [139, 140]. By February 2011, a Phase 1 trial had begun with topical formulation in pruritus [86].

Abbott was developing a tablet formulation of ABT-102 for the potential treatment of pain associated with tissue injury, inflammation and ischemia. ABT-102 was assessed in a safety and tolerability double-blind, placebo-controlled, randomized healthy volunteer trial. ABT-102 potently and reversibly increased heat pain thresholds and reduced painfulness of suprathreshold oral/cutaneous heat (see above). Apart from a significant hyperthermic effect that was disclosed as well, no other relevant serious safety findings have been reported. The most frequently reported adverse events were sensations of feeling hot or cold, hot flushes, altered taste sensation, and oral hypoesthesias or dysesthesias [109, 134, 135].

AstraZeneca was developing AZD-1386 for the potential oral treatment of chronic nociceptive pain and gastroesophageal reflux disease (GERD). In April 2008, an active- 
controlled, placebo-controlled, randomized, double-blind Phase 2 trial (NCT00672646, D5090C00010) was initiated in subjects with pain due to third molar extraction. A total of 103 male patients were enrolled into the study. AZD-1386 (55 mg per os) caused significant pain relief. Although only a modest increase in body temperature ( $\sim 0.4{ }^{\circ} \mathrm{C}$ in average) was noticed in most patients, exceeding $38^{\circ} \mathrm{C}$ in one individual, AZD1386 was discontinued in 2010 from development in chronic pain due to liver enzyme elevations [141, 142]. In 2009, AZD-1386 was evaluated in a six week multicentre proof of concept study with a double-blind, placebo controlled, randomised, adaptive dose-finding design in patients with osteoarthritis of the knee. The trial aimed to evaluate the efficacy, safety, tolerability and PK of different oral doses of AZD1386 (30 and $90 \mathrm{mg}$ ) and placebo. Although the observed plasma concentrations of AZD1386 were in agreement with what was expected and highest observed plasma concentration was $7520 \mathrm{nmol} / \mathrm{L}$, AZD1386 was not effective in reducing pain compared to placebo at any of the doses tested. A majority of the adverse events were mild to moderate in intensity. The most common types of adverse events included altered sensations/sensory perceptions in the mouth and feelings of warmth and coldness. Burns of mild to moderate intensity were reported in eight patients on AZD1386 (see also above). None of the burns were classified as a serious adverse event and none of the affected patients discontinued due to these events. There was no difference in mean body temperature between AZD1386 and placebo and no apparent differences between treatment groups in other vital signs [143].

A Phase 2 trial with GRC-6211 (Glenmark-Eli Lilly) for ostheoarthritic pain was suspended due to undisclosed reasons. Additional indications include incontinence and neuropathic pain [144].

Merck was developing MK-2295 (NGD-8243; MRK2295) for the potential treatment of pain and cough. As discussed above, MK-2295 has markedly increased the noxious heat pain threshold in humans, placing the study participants at the risk of scalding injury. For example, only $66 \%$ of individuals on $25 \mathrm{mg}$ of MK-2295 found sipped $70{ }^{\circ} \mathrm{C}$ water too hot for rapid consumption compared to every person in the control group. These findings question the clinical safety of MK-2295 (and maybe all TRPV1 antagonists) [145].

Japan Tobacco was developing the TRPV1 antagonist, JTS-653, for the potential treatment of pain and overactive bladder. However, last year the development of JTS-653 in pain was discontinued for unknown reasons [146].

\section{CONCLUSIONS}

The discovery that some TRP channels are expressed in nociceptive neurons has spawned extensive research efforts to understand the role of these channels in the initiation and maintenance of pain conditions and to identify potent and selective small molecule antagonists that can be exploited for therapeutic purposes.

In particular, TRPV1 is a sensory channel able to sense a large range of structurally different chemicals and to be operated by noxiuos heat and acidic media. Moreover, TRPV1 is sensitized by several inflammatory mediators that lower its thermal threshold of activation, resulting in nociceptor activation/sensitization at physiologic temperatures. TRPV1 antagonists developed so far demonstrated a great analgesic activity in preclinical models of inflammatory and neuropathic pain. Thus, TRPV1 represents a plausible therapeutic target for novel analgesics and the use of TRPV1 antagonists are predicted to inhibit the sensation of ongoing or burning pain that is reported by patients suffering from chronic pain, therefore offering an unprecedented advantage in selectively inhibiting painful signalling from where it is initiated. Given that many of the conditions driving tissue injury result in an increase in TRPV1 in the nociceptors, there may be an additional therapeutic advantage.

Recently, the pharmaceutical industry showed great success in the identification and development of potent small molecule TRPV1 antagonist candidates. To date, at least fifteen compounds entered Phase 1 clinical trials and five of these agents have progressed into Phase 2 'proof-of-concept' studies.

Since TRPV1 is mainly located at the periphery, where the pain pathway begins, it was hoped that TRPV1 blockade (antagonism) in humans would have been devoid of sideeffects that plague the clinical use of centrally-acting analgesic agents. Unfortunately, these expectations were recently replaced by cautious optimism. Indeed, perhaps not unexpectedly given the prominent role of TRPV1 in thermosensation, some of these antagonists showed worrisome adverse effects such as hyperthermia (e.g. AMG517, ABT-102, JTS653, AZD-1386, MK-2295) and impaired noxious heat sensation in preclinical animals and men (e.g. SB-705498, MK2295 and AZD-1386). These unwanted effects caused the withdrawal of several molecules from clinical trials.

The results of the completed Phase 2 trials will be likely released soon. If the promise of these compounds from preclinical and Phase 1 work is confirmed by the proof-ofconcept studies, TRPV1 antagonists may represent the first mechanistically novel class of analgesic drugs for many years. Moreover, recent reports of TRPV1 antagonists that do not affect core body temperature in preclinical species suggest a potential opportunity to reduce at least this important side effect.

\section{CONFLICT OF INTEREST}

MT and RG are PharmEste employees.

\section{ACKNOWLEDGEMENTS}

Declared none.

\section{REFERENCES}

[1] http://www.cnn.com/2008/health/conditions/04/28/pain

[2] Campbell J, Basbaum A, Dray A, Dubner R, Dworkin R, Sang C. Emerging strategies for the treatment of neuropathic pain. IASP Press, Seattle, WA, 2006.

[3] Gidal BE. New and emerging treatment options for neuropathic pain. Am J Manag Care 2006; 12(9 Suppl): S269-78.

[4] Katz WA, Barkin RL. Dilemmas in chronic/persistent pain management. Am J Ther 2008; 15(3): 256-64.

[5] Gallagher RM, Rosenthal LJ. Chronic pain and opiates: balancing pain control and risks in long-term opioid treatment. Arch Phys Med Rehabil 2008; 89(3 Suppl 1): S77-82.

[6] http://www.opiates.com/prescription-painkillers-addiction.html.

[7] Basbaum AI, Julius D. Toward better pain control. Sci Am 2006; 294(6): 60-7.

[8] Caterina MJ. Transient receptor potential ion channels as participants in thermosensation and thermoregulation. Am J Physiol Regul Integr Comp Physiol 2007; 292(1): R64-76. 
[9] Caterina MJ, Julius D. The vanilloid receptor: a molecular gateway to the pain pathway. Annu Rev Neurosci 2001; 24: 487-517.

[10] Ferrer-Montiel A, Garcia-Martinez C, Morenilla-Palao C, et al. Molecular architecture of the vanilloid receptor. Insights for drug design. Eur J Biochem 2004; 271(10): 1820-6.

[11] Immke DC, Gavva NR. The TRPV1 receptor and nociception. Semin Cell Dev Biol 2006; 17(5): 582-91.

[12] Di Marzo V, Blumberg PM, Szallasi A. Endovanilloid signaling in pain. Curr Opin Neurobiol 2002; 12(4): 372-9.

[13] Suh YG, Oh U. Activation and activators of TRPV1 and their pharmaceutical implication. Curr Pharm Des 2005; 11(21): 268798.

[14] Wang H, Woolf CJ. Pain TRPs. Neuron 2005; 46(1): 9-12.

[15] Hangay O. A Paprika'ro'1, Tekintettel a Re'gi Fu“ szerekre (On peppers, with special regard to old spices). Szammeb Imre Nyomdàja, Székes-Fehérvàr 1887.

[16] Turnbull A. Tincture of capsaicin as a remedy for chilblains and toothache. Dublin Free Press 1850; 1: 95-6.

[17] Hogyes E. Beitrage zur physiologischen wirkung der bestandteile des Capsicum annum. Arch Exp Pathol Pharmakol 1878; 9: 11730 .

[18] Jancso N, Jancso A. Desensitization of sensory nerve endings. Kísérletes Orvostudomány 1949; 2 (2 (Suppl): 15.

[19] Jancso N, Jancso-Gabor A, Szolcsanyi J. Direct evidence for neurogenic inflammation and its prevention by denervation and by pretreatment with capsaicin. Br J Pharmacol Chemother 1967; 31(1): $138-51$.

[20] Jancso G, Kiraly E, Jancso-Gabor A. Pharmacologically induced selective degeneration of chemosensitive primary sensory neurones. Nature 1977; 270(5639): 741-3.

[21] Szolcsanyi J. A pharmacological approach to elucidation of the role of different nerve fibres and receptor endings in mediation of pain. J Physiol (Paris) 1977; 73(3): 251-9.

[22] Szallasi A, Blumberg PM. Resiniferatoxin, a phorbol-related diterpene, acts as an ultrapotent analog of capsaicin, the irritant constituent in red pepper. Neuroscience 1989; 30(2): 515-20.

[23] Szolcsanyi J, Bartho L. Capsaicin-sensitive non-cholinergic excitatory innervation of the guinea-pig tracheobronchial smooth muscle. Neurosci Lett 1982; 34(3): 247-51.

[24] Maggi CA, Meli A. The sensory-efferent function of capsaicinsensitive sensory neurons. Gen Pharmacol 1988; 19(1): 1-43.

[25] Holzer P. Capsaicin: cellular targets, mechanisms of action, and selectivity for thin sensory neurons. Pharmacol Rev 1991; 43(2): 143-201.

[26] Szallasi A, Blumberg PM. Vanilloid (Capsaicin) receptors and mechanisms. Pharmacol Rev 1999; 51(2): 159-212.

[27] Caterina MJ, Schumacher MA, Tominaga M, Rosen TA, Levine JD, Julius D. The capsaicin receptor: a heat-activated ion channel in the pain pathway. Nature 1997; 389(6653): 816-24.

[28] Caterina MJ, Leffler A, Malmberg AB, et al. Impaired nociception and pain sensation in mice lacking the capsaicin receptor. Science 2000; 288(5464): 306-13.

[29] Davis JB, Gray J, Gunthorpe MJ, et al. Vanilloid receptor-1 is essential for inflammatory thermal hyperalgesia. Nature 2000; 405(6783): 183-7.

[30] Christoph T, Gillen C, Mika J, et al. Antinociceptive effect of antisense oligonucleotides against the vanilloid receptor VR1/TRPV1. Neurochem Int 2007; 50(1): 281-90.

[31] Christoph T, Grunweller A, Mika J, et al. Silencing of vanilloid receptor TRPV1 by RNAi reduces neuropathic and visceral pain in vivo. Biochem Biophys Res Commun 2006; 350(1): 238-43.

[32] Kasama S, Kawakubo M, Suzuki T, Nishizawa T, Ishida A, Nakayama J. RNA interference-mediated knock-down of transient receptor potential vanilloid 1 prevents forepaw inflammatory hyperalgesia in rat. Eur J Neurosci 2007; 25(10): 2956-63.

[33] Knotkova H, Pappagallo M, Szallasi A. Capsaicin (TRPV1 Agonist) therapy for pain relief: farewell or revival? Clin J Pain 2008; 24(2): 142-54

[34] Reynolds JEF. Martindale: the extra pharmacopoeia. Royal Pharmaceutical Society $1999 ; 32$ nd edn.

[35] Britain. BMARPSoG. British national formulary. BMA 2003; (No 45).

[36] http://clinicaltrials.gov/ct2/show/NCT00804154?term=Resiniferatoxin\&rank=1.
[37] Nilius B, Owsianik G, Voets T, Peters JA. Transient receptor potential cation channels in disease. Physiol Rev 2007; 87(1): 165217.

[38] Geppetti P, Holzer P. Neurogenic inflammation. Boca Raton: CRC Press 1996.

[39] Butler CA, Heaney LG. Neurogenic inflammation and asthma. Inflamm Allergy Drug Targets 2007; 6(2): 127-32.

[40] Trevisani M, Smart D, Gunthorpe MJ, et al. Ethanol elicits and potentiates nociceptor responses via the vanilloid receptor-1. Nat Neurosci 2002; 5(6): 546-51.

[41] Patapoutian A, Peier AM, Story GM, Viswanath V. ThermoTRP channels and beyond: mechanisms of temperature sensation. Nat Rev Neurosci 2003; 4(7): 529-39.

[42] Siemens J, Zhou S, Piskorowski R, et al. Spider toxins activate the capsaicin receptor to produce inflammatory pain. Nature 2006; 444(7116): 208-12.

[43] Szallasi A, Cortright DN, Blum CA, Eid SR. The vanilloid receptor TRPV1: 10 years from channel cloning to antagonist proof-ofconcept. Nat Rev Drug Discov 2007; 6(5): 357-72.

[44] Cromer BA, McIntyre P. Painful toxins acting at TRPV1. Toxicon 2008; 51(2): 163-73.

[45] Pingle SC, Matta JA, Ahern GP. Capsaicin receptor: TRPV1 a promiscuous TRP channel. Handb Exp Pharmacol 2007; 179: 15571.

[46] Ohkawara S, Tanaka-Kagawa T, Furukawa Y, Nishimura T, Jinno $\mathrm{H}$. Activation of the human transient receptor potential vanilloid subtype 1 by essential oils. Biol Pharm Bull 2010; 33(8): 1434-7.

[47] Flores CM, Vasko MR. The deorphanization of TRPV1 and the emergence of octadecadienoids as a new class of lipid transmitters Mol Interv 2010; 10(3): 137-40.

[48] Bohlen CJ, Priel A, Zhou S, King D, Siemens J, Julius D. A bivalent tarantula toxin activates the capsaicin receptor, TRPV1, by targeting the outer pore domain. Cell 2010; 141(5): 834-45.

[49] Patwardhan AM, Akopian AN, Ruparel NB, et al. Heat generates oxidized linoleic acid metabolites that activate TRPV1 and produce pain in rodents. J Clin Invest 2010; 120(5): 1617-26.

[50] Spicarova D, Palecek J. Tumor necrosis factor alpha sensitizes spinal cord TRPV1 receptors to the endogenous agonist $\mathrm{N}$ oleoyldopamine. J Neuroinflammation 2010; 7: 49.

[51] Vellani V, Mapplebeck S, Moriondo A, Davis JB, McNaughton PA. Protein kinase $\mathrm{C}$ activation potentiates gating of the vanilloid receptor VR1 by capsaicin, protons, heat and anandamide. J Physiol 2001; 534(Pt 3): 813-25.

[52] Amadesi S, Nie J, Vergnolle N, et al. Protease-activated receptor 2 sensitizes the capsaicin receptor transient receptor potential vanilloid receptor 1 to induce hyperalgesia. J Neurosci 2004; 24(18): 4300-12.

[53] Vellani V, Kinsey AM, Prandini M, et al. Protease activated receptors 1 and 4 sensitize TRPV1 in nociceptive neurones. Mol Pain 2010; 6(1): 61 .

[54] Gunthorpe MJ, Benham CD, Randall A, Davis JB. The diversity in the vanilloid (TRPV) receptor family of ion channels. Trends Pharmacol Sci 2002; 23(4): 183-91.

[55] Crandall M, Kwash J, Yu W, White G. Activation of protein kinase $\mathrm{C}$ sensitizes human VR1 to capsaicin and to moderate decreases in $\mathrm{pH}$ at physiological temperatures in Xenopus oocytes. Pain 2002; 98(1-2): 109-17.

[56] Fischer MJ, Leffler A, Niedermirtl F, et al. The general anesthetic propofol excites nociceptors by activating Trpv1 and Trpal rather than Gabaa receptors. J Biol Chem 2010; 285(45): 34781-92.

[57] Reeh PW, Petho G. Nociceptor excitation by thermal sensitization-a hypothesis. Prog Brain Res 2000; 129: 39-50.

[58] Premkumar LS, Ahern GP. Induction of vanilloid receptor channel activity by protein kinase C. Nature 2000; 408(6815): 985-90.

[59] Tominaga M, Wada M, Masu M. Potentiation of capsaicin receptor activity by metabotropic ATP receptors as a possible mechanism for ATP-evoked pain and hyperalgesia. Proc Natl Acad Sci U S A 2001; 98(12): 6951-6.

[60] Kagaya M, Lamb J, Robbins J, Page CP, Spina D. Characterization of the anandamide induced depolarization of guinea-pig isolated vagus nerve. Br J Pharmacol 2002; 137(1): 39-48.

[61] Olah Z, Karai L, Iadarola MJ. Protein kinase C(alpha) is required for vanilloid receptor 1 activation. Evidence for multiple signaling pathways. J Biol Chem 2002; 277(38): 35752-9.

[62] Bhave G, Hu HJ, Glauner KS, et al. Protein kinase C phosphorylation sensitizes but does not activate the capsaicin receptor transient 
receptor potential vanilloid 1 (TRPV1). Proc Natl Acad Sci U S A 2003; 100(21): 12480-5.

[63] Varga A, Bolcskei K, Szoke E, et al. Relative roles of protein kinase $\mathrm{A}$ and protein kinase $\mathrm{C}$ in modulation of transient receptor potential vanilloid type 1 receptor responsiveness in rat sensory neurons in vitro and peripheral nociceptors in vivo. Neuroscience 2006; 140(2): 645-57.

[64] Vetter I, Wyse BD, Monteith GR, Roberts-Thomson SJ, Cabot PJ. The mu opioid agonist morphine modulates potentiation of capsaicin-evoked TRPV1 responses through a cyclic AMP-dependent protein kinase A pathway. Mol Pain 2006; 2: 22.

[65] Zhang X, McNaughton PA. Why pain gets worse: the mechanism of heat hyperalgesia. J Gen Physiol 2006; 128(5): 491-3.

[66] Prescott ED, Julius D. A modular PIP2 binding site as a determinant of capsaicin receptor sensitivity. Science 2003; 300(5623): 1284-8.

[67] Brauchi S, Orta G, Mascayano C, et al. Dissection of the components for PIP2 activation and thermosensation in TRP channels. Proc Natl Acad Sci U S A 2007; 104(24): 10246-51.

[68] Lishko PV, Procko E, Jin X, Phelps CB, Gaudet R. The ankyrin repeats of TRPV1 bind multiple ligands and modulate channel sensitivity. Neuron 2007; 54(6): 905-18.

[69] Stein AT, Ufret-Vincenty CA, Hua L, Santana LF, Gordon SE. Phosphoinositide 3-kinase binds to TRPV1 and mediates NGFstimulated TRPV1 trafficking to the plasma membrane. J Gen Physiol 2006; 128(5): 509-22.

[70] Lukacs V, Thyagarajan B, Varnai P, Balla A, Balla T, Rohacs T. Dual regulation of TRPV1 by phosphoinositides. J Neurosci 2007; 27(26): 7070-80.

[71] Mohapatra DP, Nau C. Regulation of Ca2+-dependent desensitization in the vanilloid receptor TRPV1 by calcineurin and cAMPdependent protein kinase. J Biol Chem 2005; 280(14): 13424-32.

[72] Bhave G, Zhu W, Wang H, Brasier DJ, Oxford GS, Gereau RWt. cAMP-dependent protein kinase regulates desensitization of the capsaicin receptor (VR1) by direct phosphorylation. Neuron 2002; 35(4): 721-31.

[73] Mohapatra DP, Nau C. Desensitization of capsaicin-activated currents in the vanilloid receptor TRPV1 is decreased by the cyclic AMP-dependent protein kinase pathway. J Biol Chem 2003; 278(50): 50080-90.

[74] Numazaki M, Tominaga T, Takeuchi K, Murayama N, Toyooka H, Tominaga M. Structural determinant of TRPV1 desensitization interacts with calmodulin. Proc Natl Acad Sci U S A 2003; 100(13): 8002-6.

[75] Rosenbaum T, Gordon-Shaag A, Munari M, Gordon SE. $\mathrm{Ca} 2+/$ calmodulin modulates TRPV1 activation by capsaicin. J Gen Physiol 2004; 123(1): 53-62.

[76] Jung J, Shin JS, Lee SY, et al. Phosphorylation of vanilloid receptor 1 by $\mathrm{Ca} 2+/$ calmodulin-dependent kinase II regulates its vanilloid binding. J Biol Chem 2004; 279(8): 7048-54.

[77] Malmberg A, Bley K. Turning up the Heat on Pain: TRPV1 Receptors in Pain and Inflammation. Birkhäuser, Basel, Switzerland 2005.

[78] Gunthorpe MJ, Szallasi A. Peripheral TRPV1 receptors as targets for drug development: new molecules and mechanisms. Curr Pharm Des 2008; 14(1): 32-41.

[79] Roberts LA, Connor M. TRPV1 antagonists as a potential treatment for hyperalgesia. Recent Pat CNS Drug Discov 2006; 1(1): 65-76.

[80] Gharat L, Szallasi A. Advances in the design and therapeutic use of capsaicin receptor TRPV1 agonists and antagonists. Expert Opin Thera Pat 2008; 18: 159-209.

[81] Chizh BA, O'Donnell MB, Napolitano A, et al. The effects of the TRPV1 antagonist SB-705498 on TRPV1 receptor-mediated activity and inflammatory hyperalgesia in humans. Pain 2007; 132(1-2): 132-41.

[82] Faltynek C, Gomtsyan A. Vanilloid receptor TRPV1 in drug discovery: targeting pain and other pathological disorders. John Wiley\&Sons 2009.

[83] http://www.pharmeste.com/home.asp?op=interna\&id=2\&id_pag=10\&tit=Pipeline.

[84] http://www.daewoong.co.kr/www_pharm/english_new/products/pipeline.asp.

[85] http://clinicaltrials.gov/ct2/show/NCT00960180.

[86] http://www.gsk.com/investors/product_pipeline/docs/GSKproduct-pipeline-Feb-2012.pdf.
[87] Bevan S, Hothi S, Hughes G, et al. Capsazepine: a competitive antagonist of the sensory neurone excitant capsaicin. Br J Pharmacol 1992; 107(2): 544-52.

[88] Weil A, Moore SE, Waite NJ, Randall A, Gunthorpe MJ. Conservation of functional and pharmacological properties in the distantly related temperature sensors TRVP1 and TRPM8. Mol Pharmacol 2005; 68(2): 518-27.

[89] Xing H, Chen M, Ling J, Tan W, Gu JG. TRPM8 mechanism of cold allodynia after chronic nerve injury. J Neurosci 2007; 27(50): 13680-90.

[90] Walker KM, Urban L, Medhurst SJ, et al. The VR1 antagonist capsazepine reverses mechanical hyperalgesia in models of inflammatory and neuropathic pain. J Pharmacol Exp Ther 2003; 304(1): 56-62.

[91] Holzer P. The pharmacological challenge to tame the transient receptor potential vanilloid-1 (TRPV1) nocisensor. Br J Pharmacol 2008; 22: 22 .

[92] Gavva NR, Tamir R, Klionsky L, et al. Proton activation does not alter antagonist interaction with the capsaicin-binding pocket of TRPV1. Mol Pharmacol 2005; 68(6): 1524-33.

[93] Lehto SG, Tamir R, Deng H, et al. Antihyperalgesic effects of (R,E)-N-(2-hydroxy-2,3-dihydro-1H-inden-4-yl)-3-(2-(piperidin-1yl)-4-(trifluorom ethyl)phenyl)-acrylamide (AMG8562), a novel transient receptor potential vanilloid type 1 modulator that does not cause hyperthermia in rats. J Pharmacol Exp Ther 2008; 326(1): 218-29.

[94] Seabrook GR, Sutton KG, Jarolimek W, et al. Functional properties of the high-affinity TRPV1 (VR1) vanilloid receptor antagonist (4hydroxy-5-iodo-3-methoxyphenylacetate ester) iodo-resiniferatoxin. J Pharmacol Exp Ther 2002; 303(3): 1052-60.

[95] Gavva NR, Klionsky L, Qu Y, et al. Molecular determinants of vanilloid sensitivity in TRPV1. J Biol Chem 2004; 279(19): 2028395.

[96] Neelands TR, Jarvis MF, Han P, Faltynek CR, Surowy CS. Acidification of rat TRPV1 alters the kinetics of capsaicin responses. Mol Pain 2005; $1: 28$.

[97] http://www.glenmarkpharma.com/media/pdf/releases/GRC_6211. pdf.

[98] http://www.glenmarkpharma.com/research/clinical.html.

[99] Pomonis JD, Harrison JE, Mark L, Bristol DR, Valenzano KJ, Walker K. N-(4-Tertiarybutylphenyl)-4-(3-cholorphyridin-2-yl)tetr-ahydropyrazine -1(2H)-carbox-amide (BCTC), a novel, orally effective vanilloid receptor 1 antagonist with analgesic properties: II. In: vivo characterization in rat models of inflammatory and neuropathic pain. J Pharmacol Exp Ther 2003; 306(1): 387-93.

[100] Yamamoto W, Sugiura A, Nakazato-Imasato E, Kita Y. Characterization of primary sensory neurons mediating static and dynamic allodynia in rat chronic constriction injury model. J Pharm Pharmacol 2008; 60(6): 717-22.

[101] Swanson DM, Dubin AE, Shah C, et al. Identification and biological evaluation of 4-(3-trifluoromethylpyridin-2-yl)piperazine-1carboxylic acid (5-trifluoromethylpyridin-2-yl)amide, a high affinity TRPV1 (VR1) vanilloid receptor antagonist. J Med Chem 2005; 48(6): 1857-72.

[102] Zhong C, Gauvin D, Mikusa J, et al. The novel and potent trpv1 antagonist, A-784168, is a broad-spectrum analgesic in preclinical pain models. Washington, DC: Society for Neuroscience 2005.

[103] Cui M, Honore P, Zhong C, et al. TRPV1 receptors in the CNS play a key role in broad-spectrum analgesia of TRPV1 antagonists. J Neurosci 2006; 26(37): 9385-93.

[104] Watabiki T, Kiso T, Kuramochi T, et al. Amelioration of neuropathic pain by novel transient receptor potential vanilloid 1 antagonist AS1928370 in rats without hyperthermic effect. J Pharmacol Exp Ther 2011; 336(3): 743-50.

[105] http://www.acsmedchem.org/mediabstracts2011.pdf.

[106] Brederson JD, Chu KL, Reilly RM, et al. TRPV1 antagonist, A889425 , inhibits mechanotransmission in a subclass of rat primary afferent neurons following peripheral inflammation. Synapse 2011; 66(3): 187-95.

[107] Honore P, Wismer CT, Mikusa J, et al. A-425619 [1-isoquinolin-5yl-3-(4-trifluoromethyl-benzyl)-urea], a novel transient receptor potential type V1 receptor antagonist, relieves pathophysiological pain associated with inflammation and tissue injury in rats. J Pharmacol Exp Ther 2005; 314(1): 410-21. 
[108] Trevisani M, Fruttarolo F, Pavani M, et al. V377, A Potent TRPV1 antagonist for pain management. European Opioid Conference (EOC) - European Neuropeptide Club (ENC) joint meeting 2008.

[109] http://clinicaltrials.gov/ct2/results?term=ABT-102.

[110] Surowy CS, Neelands TR, Bianchi BR, et al. (R)-(5-tert-butyl-2,3dihydro-1H-inden-1-yl)-3-(1H-indazol-4-yl)-urea (ABT-102) blocks polymodal activation of transient receptor potential vanilloid 1 receptors in vitro and heat-evoked firing of spinal dorsal horn neurons in vivo. J Pharmacol Exp Ther 2008; 326(3): 879-88.

[111] Gomtsyan A, Bayburt EK, Schmidt RG, et al. Identification of (R)1-(5-tert-butyl-2,3-dihydro-1H-inden-1-yl)-3-(1H-indazol-4-yl)urea (ABT-102) as a potent TRPV1 antagonist for pain management. J Med Chem 2008; 51(3): 392-5.

[112] Brown BS, Keddy R, Perner RJ, et al. Discovery of TRPV1 antagonist ABT-116. Bioorg Med Chem Lett 2010; 20(11): 3291-4.

[113] Puttfarcken PS, Han P, Joshi SK, et al. A-995662 [(R)-8-(4methyl-5-(4-(trifluoromethyl)phenyl)oxazol-2-ylamino)-1,2,3,4tetrahydr onaphthalen-2-ol], a novel, selective TRPV1 receptor antagonist, reduces spinal release of glutamate and CGRP in a rat knee joint pain model. Pain 2010; 150(2): 319-26.

[114] Maher MP, Bhattacharya A, Ao $\mathrm{H}$, et al. Characterization of 2(2,6-dichloro-benzyl)-thiazolo[5,4-d]pyrimidin-7-yl]-(4-trifluoromethyl-phenyl) -amine (JNJ-39729209) as a novel TRPV1 antagonist. Eur J Pharmacol 2011; 663(1-3): 40-50.

[115] Watabiki T, Kiso T, Tsukamoto M, Aoki T, Matsuoka N. Intrathecal administration of AS1928370, a transient receptor potential vanilloid 1 antagonist, attenuates mechanical allodynia in a mouse model of neuropathic pain. Biol Pharm Bull 2011; 34(7): 1105-8.

[116] Wallace MS. Ziconotide: a new nonopioid intrathecal analgesic for the treatment of chronic pain. Expert Rev Neurother 2006; 6(10): 1423-8.

[117] Menendez L, Juarez L, Garcia E, Garcia-Suarez O, Hidalgo A, Baamonde A. Analgesic effects of capsazepine and resiniferatoxin on bone cancer pain in mice. Neurosci Lett 2006; 393(1): 70-3.

[118] Brown DC, Iadarola MJ, Perkowski SZ, et al. Physiologic and antinociceptive effects of intrathecal resiniferatoxin in a canine bone cancer model. Anesthesiology 2005; 103(5): 1052-9.

[119] Hori T. Capsaicin and central control of thermoregulation. Pharmacol Ther 1984; 26(3): 389-416.

[120] Bannon A, Davis J, Zhu D, et al. Involvement of TRPV1 in the regulation of body temperature in rats and mice. Society for Neuroscience Annual Meeting Program; 2004; San Diego, CA: 2004.

[121] Gavva NR, Bannon AW, Surapaneni S, et al. The vanilloid receptor TRPV1 is tonically activated in vivo and involved in body temperature regulation. J Neurosci 2007; 27(13): 3366 -74.

[122] Romanovsky AA, Almeida MC, Garami A, et al. The transient receptor potential vanilloid-1 channel in thermoregulation: a thermosensor it is not. Pharmacol Rev 2009; 61(3): 228-61.

[123] Gavva NR. Body-temperature maintenance as the predominant function of the vanilloid receptor TRPV1. Trends Pharmacol Sci 2008; 19: 19.

[124] Gavva NR, Treanor JJ, Garami A, et al. Pharmacological blockade of the vanilloid receptor TRPV1 elicits marked hyperthermia in humans. Pain 2008; 136(1-2): 202-10.

[125] Steiner AA, Turek VF, Almeida MC, et al. Nonthermal activation of transient receptor potential vanilloid-1 channels in abdominal viscera tonically inhibits autonomic cold-defense effectors. J Neurosci 2007; 27(28): 7459-68.

[126] Gavva NR, Bannon AW, Hovland DN, et al. Repeated administration of vanilloid receptor TRPV1 antagonists attenuates hyperthermia elicited by TRPV1 blockade. J Pharmacol Exp Ther 2007; 323(1): 128-37.
[127] Reilly R, McDonald H, Puttfarcken P, et al. Novel TRPV1 receptor antagonists that partially block acid activation. In vitro pharmacology predicts effects on core body temperature and in vivo efficacy. J Pharmacol Exp Ther 2012; In Press.

[128] Nash MS, McIntyre P, Groarke A, et al. BCTP, a classic polymodal inhibitor of TRPV1 with a reduced liability for hyperthermia, is analgesic and ameliorates visceral hypersensitivity. J Pharmacol Exp Ther 2012; 342(2): 389-98.

[129] Garcia-Martinez C, Humet M, Planells-Cases R, et al. Attenuation of thermal nociception and hyperalgesia by VR1 blockers. Proc Natl Acad Sci U S A 2002; 99(4): 2374-9.

[130] Tang L, Chen Y, Chen Z, Blumberg PM, Kozikowski AP, Wang ZJ. Antinociceptive pharmacology of N-(4-chlorobenzyl)-N'-(4hydroxy-3-iodo-5-methoxybenzyl) thiourea, a high-affinity competitive antagonist of the transient receptor potential vanilloid 1 receptor. J Pharmacol Exp Ther 2007; 321(2): 791-8.

[131] Eid SR. To feel or not to feel - targeting the heat sensor TRPV1 for pain treatment. keystone meeting on neurobiology of pain and analgesia http://wwwkeystonesymposiaorg; Santa Fe, New Mexico; 2009.

[132] Chizh BA, Sang CN. Use of sensory methods for detecting target engagement in clinical trials of new analgesics. Neurotherapeutics 2009; 6(4): 749-54.

[133] Eid SR. TRPV1 Antagonists: are they too hot to handle? 3rd annual Pain Therapeutics Summit in Summit http://wwwarrowheadpublisherscom/conferences/pain-therapeutics2009/agenda/; 2009; Summit, New Jersey: 2009.

[134] Othman AA, Nothaft W, Awni WM, Dutta S. Pharmacokinetics of the TRPV1 antagonist ABT-102 in healthy human volunteers: population analysis of data from 3 phase 1 trials. J Clin Pharmacol 2012; 52(7): 1028-41.

[135] Rowbotham MC, Nothaft W, Duan WR, et al. Oral and cutaneous thermosensory profile of selective TRPV1 inhibition by ABT-102 in a randomized healthy volunteer trial. Pain 2011; 152(5): 1192200.

[136] http://clinicaltrials.gov/ct2/show/NCT00969787?term=05195\&ra$\mathrm{nk}=1$.

[137] http://www.pharmeste.com/include/PHE377.pdf.

[138] http://clinicaltrials.gov/ct2/show/NCT00281684?cond.

[139] http://clinicaltrials.gov/ct2/show/NCT01424514?term=705498\&rank $=1$.

[140] http://clinicaltrials.gov/ct2/show/NCT01476098?term=705498\&rank=4.

[141] Krarup AL, Ny L, Astrand M, et al. Randomised clinical trial: the efficacy of a transient receptor potential vanilloid 1 antagonist AZD1386 in human oesophageal pain. Aliment Pharmacol Ther 2011;33(10): 1113-22.

[142] http://www.astrazenecaclinicaltrials.com/other-drug-products/discontinued-products/AZD1386/?expandAll=true.

[143] http://www.astrazenecaclinicaltrials.com/_mshost800325/content/ clinical-trials/resources/pdf/D5090C00019.

[144] http://www.glenmarkpharma.cz/gln3.php?lang=en.

[145] http://www.neurogen.com/index.php?option=com_content $\&$ view= article\&id=47\&Itemid=2\&phpMyAdmin=34a2390 $\mathrm{c} 0$ eecf801a871d79668695b95.

[146] http://www.jti.co.jp/investors/others/12g3_2/pdf/20110831_01.pdf.

[147] http://clinicaltrials.gov/ct2/show/NCT00969787?term=DWP$05195 \&$ rank $=3$.

[148] http://clinicaltrials.gov/ct2/show/NCT01557010?term=DWP$05195 \&$ rank $=2$.

[149] http://www.astrazeneca.com/_mshost3690701/content/resources/media/investors/10809118/AZ̄N-Q2-2010-Pipeline-Summary.pdf. 